\section{Nodular malignant melanoma and multiple squamous cell carcinomas in a patient treated by photochemotherapy for psoriasis}

We describe a patient suffering from psoriasis who developed a nodular malignant melanoma and three squamous cell carcinomas after treatment with psoralen and ultraviolet light A (PUVA). So far as we know this is the first report of invasive melanoma in a patient treated with this modality.

\section{Case history}

A 61 year old man had had a history of psoriasis for 40 years. Treatments had included tar, dithranol, and topical steroids, but he had never received $x$ ray therapy, arsenic, or cytotoxic agents and had no cutaneous malignancy before starting PUVA. During the second world war he had spent three years in Egypt but subsequently worked as a clerk in London and did not expose himself to natural or artificial forms of ultraviolet light. Examination before photochemotherapy showed plaque psoriasis of $20^{\circ}$ " of body surface. PUVA was instituted in March 1979. The dose of 8-methoxypsoralens was $50 \mathrm{mg}$ and the starting dose of ultraviolet A $1 \mathrm{~J} / \mathrm{cm}^{2}$. He was treated wo or three times weekly until the psoriasis cleared and then maintained with treatment once every two or three weeks. In February 1983, after a cumulative dose of ultraviolet $A$ of $419 \mathrm{~J} \mathrm{~cm} \mathrm{~cm}^{2}$ in 176 sessions, he developed three scaly lesions on the anterior chest. Histologically two of these were squamous cell carcinomas and the third a solar keratosis. Examination also showed many PUVA lentigines distributed widely. In May an area of Bowen's disease was excised from the $\mathrm{V}$ of the chest. Three months later one squamous cell carcinoma and three further solar keratoses were removed from the dorsa of the hands. PUVA was discontinued (cumulative dose $461 \mathrm{~J} \mathrm{~cm}^{2}$ in 184 sessions). Unfortunately, control of his psoriasis proved impossible with topical treatment and PCVA was reintroduced in October for a further 10 sessions and $36.5 \mathrm{~J} / \mathrm{cm}^{2}$. It was finally stopped in December 1983

At follow up in April 1984 a symptomless, pigmented nodule $1 \mathrm{~cm}$ diameter was noted on the anterior shoulder. The lesion had been growing rapidly for eight weeks and he was not aware of a previous pigmented lesion on that site. The lesion was excised and proved to be a nodular malignant melanoma, with spread to the subcutaneous fat (Clark's level V). There were no excessive signs of actinic damage for the patient's age and sex. A wider excision was performed one week later.

\section{Comment}

Photochemotherapy with 8-methoxypsoralen and ultraviolet $\mathrm{A}$ is an effective treatment for severe psoriasis and is popular with patients, as it avoids the inconvenience of some topical agents. The long term hazards of the regimen, however, are unknown and remain to be quantified. Psoralens interact with pyrimidine bases to form cross linkages in the double helix of deoxyribonucleic acid (DNA). 8-Methoxypsoralen increases the incidence of skin tumours after simulated solar exposure in albino mice. ${ }^{1}$ Evidence is accumulating that PUVA is immunosuppressive, and it has been shown to have a proliferative effect on melanocytes." These melanocytes are often large and cytologically atypical and are found within the PUVA lentigines. The increased frequency of PUVA lentigines is associated with a greater number of PUVA treatments $(\cdot 100)$, increasing age $(.35)$, and male sex."

There have been several reports of skin carcinoma in patients treated with PUVA. In a large series Stern et al found a 12-fold increased hazard of squamous cell carcinomas but not basal cell carcinomas in patients treated with PUVA compared with the general population. ${ }^{3}$ Marx et al reported the occurrence of malignant melanomas in situ induced by PUVA in patients with psoriasis.' In addition, a patient with vitiligo receiving oral psoralens followed by solar exposure developed a malignant melanoma with spread to the upper dermis only (Clark's level III).

The occurrence of malignant melanoma in our patient may have been coincidence. Marx et al estimated (using figures for the United States) that four melanomas might be expected to occur yearly world wide in all patients who have received PUVA. While we cannot definitely incriminate PUVA in the actiology of our patient's tumour, the fact that he had had three squamous cell carcinomas and an area of Bowen's disease, in the absence of any other known carcinogen, strongly suggests that PUVA was the oncogenic influence.

This case highlights the importance of careful supervision and the need for multicentre cooperation to determine the incidence of melanoma in patients with psoriasis treated with photochemotherapy.

1 Young AR, Magnus IA, Davies AC, Smith NP. A comparison of the phototherigenic potential of 8-MOP and 5-MOP in hairless albino mice exposed to n. Br J Dermatol 1983;108:507-28.

. The PUVA lentigo: an analysis of predisposing factors. F Invest Dermatol 1983;81:459-63.

Stern RS, Laird N, Melski J, Parrish JA, Fitzpatrick TB, Bleich HL. Cutaneous squamous cell carcinomata in patients treated with PUVA. N Engl f Med 1984;310:1156-61

4 Marx JL, Auerbach R, Possick P, Myrow R, Gladsleui AH, Kopf AW. Malignant melanoma-in-situ in two patients treated with psoralens and ultraviolet $A$. f Am Acad Dermatol 1983;9:904-11.

5 Forrest JB, Forrest JH. Malignant melanoma arising during drug therapy for vitiligo. f Surg Oncol 1980;12:337-40.

(Accepted 17 August 1984)

Department of Dermatology, The London Hospital, Whitechapel, London E1 1BB

DANIEL KEMMETT, MB, senior house officer

HIIZIYE RESHAD, $M B, M R C P$, senior registrar

HARVEY BAKER, MD, FRCP, consultant dermatologist

Correspondence to: Dr H Baker.

\section{Experience with routine reuse of plastic insulin syringes}

The changeover to U100 insulin was scheduled by the British Diabetic Association to start in March 1983. From late 1982 our patients were told to bring all injection equipment to their first appointment after 1 March 1983 for replacement. Nearer that date we realised that new glass svringes would not be available. As plastic syringes can be reused safely by the same patient with probable financial saving ${ }^{3}$ we agreed with our hospital pharmacist that our patients would receive plastic syringes to be used for one week each.

\section{Patients, methods, and results}

As patients were changed to U100 insulin we explained how to use the plastic syringes (Becton Dickinson $0.5 \mathrm{ml}$ or Plastipak $1 \mathrm{ml}$ insulin syringes, with fixed needles). Patients were told not to clean syringes or needles but to reinsert the needle into its cover after use and to store the syringe in a dry container in a refrigerator. At each clinic attendance patients received an internal hospital prescription for enough plastic syringes until their nex visit at the rate of one syringe a week. Additional syringes could be bought from retail chemists if necessary.

One year later we completed a questionnaire with 118 consecutive patients. They had then been taking U100 for from three to 15 months (mean $9 \cdot 8$ months), having received insulin injections for from under one year to 43 years (mean $12 \cdot 1$ years). All were taking highly purified pork or beef insulin, 39 once daily and 79 twice daily. Sixty six patients used the plastic syringes for at least seven days and 44 patients for six days or less, and eight patients used glass, not plastic syringes. The mean duration of use of

Use of plastic syringes by patients in relation to number of injections a day and duration of use of insulin. (Figures are mians. (SD))

\begin{tabular}{|c|c|c|c|}
\hline & $\begin{array}{l}\text { All } \\
\text { paticnts } \\
\text { n } 118)\end{array}$ & $\begin{array}{l}\text { Patients taking } \\
\text { once daily insulin } \\
(11-39)\end{array}$ & $\begin{array}{l}\text { Patients taking } \\
\text { twice daily insulin } \\
(\mathrm{n} \quad 79)\end{array}$ \\
\hline $\begin{array}{l}\text { Paticnts using plastic } \\
\text { syringes }\end{array}$ & 110 & 36 & 74 \\
\hline $\begin{array}{l}\text { 1) uration of use of one } \\
\text { plastic syringe (days) }\end{array}$ & $6.70 \quad 3.91)$ & $0.40 \quad(2.57)$ & $6.84(4.45)$ \\
\hline Time on insulin (years) & $12.09(10.09)$ & $14 \cdot 90(11 \cdot 16)$ & $10 \cdot 71(9 \cdot 29)$ \\
\hline $\begin{array}{l}\text { Time on U100 insulin } \\
\text { (months) }\end{array}$ & $9 \cdot 79 \quad(2 \cdot 74)$ & & \\
\hline
\end{tabular}


the plastic syringes was 6.7 days. Twenty seven patients used syringes for over seven days, one for up to 28 days. Of the 44 patients who used more than one syringe a week, 17 bought their own extra syringes, three got them from district nurses, and 23 managed to defeat the system and get them from us. The mean duration of use of plastic syringes was shorter for patients receiving one injection a day $(6 \cdot 4$ days) than for those receiving two injections a day ( 6.8 days). The group receiving once daily injections were mostly older patients who had been taking insulin for many years (table).

Of the 118 patients, 18 had never used glass syringes. Of the remaining 100,83 preferred plastic syringes and 14 glass; three had no preference. Patients who preferred glass syringes had been injecting insulin for a longer mean time $(18.8$ years) than the whole group (12.7 years). Of 31 patients who had been using glass syringes for over 20 years, however, 22 preferred plastic syringes.

No complications occurred from reuse of plastic syringes.

\section{Comment}

Our survey showed most diabetic patients prefer using plastic syringes even when they use the same one for a week. A glass U100 syringe costs this hospital $£ 4.80$ and a metal needle 13 p. A plastic syringe-needle unit such as our patients use costs $7 \cdot 2 \mathrm{p}$. Our patients used plastic syringes for a mean of 6.7 days, but this included the few patients who used syringes for less time and bought extra syringes themselves.

Patients in another area of London have been reported to use glass syringes for only about three months, ${ }^{1}$ and in Strathclyde patients used on average 1.72 non-disposable syringes and 62 nondisposable needles a year-that is, a syringe for 30 weeks and a needle for only 5.9 days. ${ }^{4}$ Using the Strathclyde figures for average duration of use, current annual cost of non-disposable U100 syringes and needles is $£ 16.32$ per patient $(£ 4.80 \div 1.72+13 \mathrm{p} \times 62)$. In London, where patients use glass syringes for less time, the annual cost is correspondingly higher; 60 disposable syringe-needle units, however, would cost $£ 4 \cdot 30$. The policy of the Department of Health and Social Security for insulin syringes is considerably more expensive than ours and should surely be changed.

We are grateful to Mr F A Dunn, principal pharmacist, for his cooperation in this project.

1 Greenough A, Cockcroft PM, Bloom A. Disposable syringes for insulin injection Br Med F 1979;i:1467-8

Hodge RH Jr, Krongaard L, Sande MA, Kaiser DL. Multiple use of disposable insulin syringe-needle units. 7AMA 1980;244:266-

作 for

disposable syringes and needles for diabetics? Br Mred 7 1983;286:369-70.

5 Collins BJ, Richardson SG, Spence BK, et al. Safety of reusing disposable plastic insulin syringes. Lancet $1983 ; 1: 559-61$.

(Accepted 12 September 1984)

Diabetic Clinic, North Middlesex Hospital, London N18 1QX

EVA LES TER, MB, FRCPATH, consultant chemical pathologist

F J WOODROFFE, MSC, FRCP, consultant physician

A J GRAN $\mathrm{T}, \mathrm{MB}, \mathrm{BS}$, clinical assistant

Correspondence to: Dr Eva Lester.

\section{Failure of single dose amoxycillin as prophylaxis against endocarditis}

The development of bacterial endocarditis remains a definite risk in patients with established valvular disease of the heart. We report bacterial endocarditis occurring in a patient after dental clearance despite the prophylactic administration of a $3 \mathrm{~g}$ oral dose of amoxycillin.

\section{Case report}

A 44 year old unemployed, unkempt alcoholic man was admitted in August 1982 with an episode of pulmonary oedema. Valvular heart disease had been recognised for seven years. Echocardiography and radiology showed left ventricular hypertrophy and mixed aortic valve disease. Blood cultures were sterile, the erythrocyte sedimentation rate was $5 \mathrm{~mm}$ in first hour, and no antibiotics had been prescribed in the past three weeks. Gross dental caries, periodontal abscesses, heavy deposits of calculus, and severe bone loss were noted affecting all his remaining 12 teeth. On 24 August complete dental clearance was performed under local anaesthetic. Antibiotic prophylaxis was given with $3 \mathrm{~g}$ amoxycillin by mouth two hours before extraction. The sutures were removed one week later with no antibiotic cover.

In October the patient was readmitted to another hospital with pulmonary oedema ascribed to poor compliance. Sedimentation rate was $40 \mathrm{~mm}$ in firs hour and the haemoglobin concentration had fallen $2 \mathrm{~g}$ to $11.5 \mathrm{~g} / \mathrm{dl}$. Blood cultures grew no pathogens. In November he was readmitted to the first hospital with a further episode of pulmonary oedema. There were no embolic phenomena and no haematuria. Sedimentation rate was $108 \mathrm{~mm}$ in first hour and the white cell count $14.5 \times 10^{9} / 1$. Haematological investigation disclosed low grade haemolysis with $\mathrm{C} 3$ and $\mathrm{IgG}$ coating of the red cells and peripheral destruction of platelets. A positive Coombs test result raised the possibility of Evans's syndrome. Two sets of blood cultures were sterile. Bacterial endocarditis was considered as part of the differential diagnosis. In general, particularly in the presence of negative blood cultures, we considered that a watching brief should be taken. Review in the outpatient clinic in January and February showed no change in his clinical condition. His final admission, in March 1983, was preceded by shortness of breath, chest pain, and diarrhoea for two days. Despite intensive treatment he deteriorated over the next 24 hours and died.

Necropsy showed a large heart $(750 \mathrm{~g})$ with severe dilatation and hypertrophy of the left ventricle. The aortic valve comprised three cusps, which were thickened, fused, and ulcerated. Haemorrhagic, friable vegetations were adherent to the ventricular aspect of the valve. The myocardium showed pale, irregular areas of softening. Numerous systemic infarcts were also present, affecting kidneys, spleen, small intestine, and brain. Histologically the aortic valve showed thrombus with an underlying inflammatory cell infiltrate and fibrosis. The myocardial lesions were typical "Bracht-Wächter bodies", infarcts in various stages of healing, many showing active organisation and fibrosis consistent with weeks or months of duration. Extensive embolisation from the valve was evident from the organising thrombi in the small arterial vessels of the heart and the multiple systemic infarcts. The kidneys showed a diffuse glomerulonephritis of membranoproliferative type. The findings indicated endocarditis of some months' duration superimposed on chronic valvular disease, presumably rheumatic in origin.

Culture of blood before death and of vegetations grew an $\alpha$ haemolytic streptococcus of group G, probably Streptococcus milleri (Streptococcal Reference Laboratory, Colindale). The organism was tolerant of amoxycillin, having a minimal inhibitory concentration of $0.025 \mathrm{mg} / 1$ and a minimal bactericidal concentration of $>10 \mathrm{mg} / 1$.

\section{Comment}

This patient had a complicated clinical course and a lack of compliance which made his management difficult. Probably the endocarditis developed after dental clearance. His erythrocyte sedimentation rate rose progressively and he developed an anaemia consistent with cardiac haemolysis. The necropsy details and associated histological findings indicated that his endocarditis was of some months' duration. It is generally considered that only dental work that causes gingival bleeding gives rise to a bacteraemia and it is therefore unlikely that the organism entered after removal of sutures.

The Working Party of the British Society for Antimicrobial Chemotherapy recommend for prophylaxis of endocarditis $3 \mathrm{~g}$ amoxycillin by mouth one hour before dental extraction. ${ }^{1}$ Our patient was given this dose of amoxycillin two hours before dental clearance on an empty stomach. No further antibiotics were given. We have no reason to suppose that the antibiotic was inadequately absorbed. Shanson et al showed in volunteers that bactericidal concentrations of amoxycillin remain in the blood for some eight hours after a $3 \mathrm{~g}$ oral dose. $^{2}$ It may not, however, be necessary to achieve circulating bactericidal concentrations of amoxycillin to prevent endocarditis. Recent work in rabbits has shown the protective effect of amoxycillin even with inoculation of amoxycillin tolerant streptococci. ${ }^{3}$ This is attributed to the prevention of adherence of bacteria. This protective effect is lost with increasing sizes of inoculum. Amoxycillin tolerant streptococci may account for up to one third of cases of endocarditis. ${ }^{3}$

No local measures to reduce the reservoir of bacteria within the periodontal pockets were taken. It has been suggested that aqueous chlorhexidine swabbed around the gingival margins may reduce the bacterial count.

We submit that our patient developed endocarditis with an amoxycillin tolerant strain despite prophylaxis because of the large inoculum size of organisms associated with extensive dental disease. This case raises important questions. Should extractions of many teeth be done in several stages in patients with heart abnormalities and serious dental disease to reduce the bacteraemic load despite the likelihood of a greater frequency of bacterial tolerance? Should two antibiotics be given in this setting, and should they be given by injection? In addition, if sutures are inserted, should antibiotic cover be employed during their subsequent removal? 